Meta

Journal des traducteurs

Translators' Journal

\title{
Effects of Specific Training on the Ability to Deal with Cultural References in Translation
}

\section{Christopher Scott-Tennent et María González Davies}

Volume 53, numéro 4, décembre 2008

URI : https://id.erudit.org/iderudit/019647ar

DOI : https://doi.org/10.7202/019647ar

Aller au sommaire du numéro

Éditeur(s)

Les Presses de l'Université de Montréal

ISSN

0026-0452 (imprimé)

1492-1421 (numérique)

Découvrir la revue

Citer cet article

Scott-Tennent, C. \& González Davies, M. (2008). Effects of Specific Training on the Ability to Deal with Cultural References in Translation. Meta, 53(4),

782-797. https://doi.org/10.7202/019647ar
Résumé de l'article

L'objectif de cette étude empirique (qui fait partie d'un projet de recherche plus large) est de découvrir les effets de la formation professionnelle du traducteur mise en place spécifiquement pour mesurer la capacité des étudiants à aborder les références culturelles, généralement considérées comme un type de segment textuel potentiellement problématique pour le traducteur. Plus particulièrement, nous nous sommes proposé de mettre en relief les différences significatives relevant de cette modalité formative, en ce qui concerne la capacité des étudiants à : (a) répérer des références culturelles dans le texte ; b) fournir de multiples options valables (variantes) afin de les traduire ; c) évaluer ces options potentielles ; d) appliquer le raisonnement lors du choix final à partir des différentes options proposées. Cette analyse raisonnée ainsi que la nature de cette formation spécifique ont été déjà largement abordées par González Davies et Scott-Tennent (2005). Dans cet article, nous centrons notre attention sur l'analyse et la discussion des effets observés. La conception de cette formation spécifique s'appuie sur une étude antérieure relative à la résolution de problèmes dans la formation spécifique de traducteurs dont la référence se trouve dans Scott-Tennent et al. (2000) et dans González-Davies et al. (2001).
Ce document est protégé par la loi sur le droit d'auteur. L'utilisation des services d’Érudit (y compris la reproduction) est assujettie à sa politique d'utilisation que vous pouvez consulter en ligne.

https://apropos.erudit.org/fr/usagers/politique-dutilisation/ 


\title{
Effects of Specific Training on the Ability to Deal with Cultural References in Translation:*
}

\author{
CHRISTOPHER SCOTT-TENNENT \\ Universitat Rovira i Virgili, Tarragona, Spain \\ cscott-tennent@uoc.edu
}

\author{
MARÍA GONZÁLEZ DAVIES \\ Universitat Ramon Llull, Barcelona, Spain \\ mariagd@blanquerna.url.edu
}

\section{RÉSUMÉ}

L'objectif de cette étude empirique (qui fait partie d'un projet de recherche plus large) est de découvrir les effets de la formation professionnelle du traducteur mise en place spécifiquement pour mesurer la capacité des étudiants à aborder les références culturelles, généralement considérées comme un type de segment textuel potentiellement problématique pour le traducteur. Plus particulièrement, nous nous sommes proposé de mettre en relief les différences significatives relevant de cette modalité formative, en ce qui concerne la capacité des étudiants à: (a) répérer des références culturelles dans le texte; b) fournir de multiples options valables (variantes) afin de les traduire; c) évaluer ces options potentielles; d) appliquer le raisonnement lors du choix final à partir des différentes options proposées. Cette analyse raisonnée ainsi que la nature de cette formation spécifique ont été déjà largement abordées par González Davies et Scott-Tennent (2005). Dans cet article, nous centrons notre attention sur l'analyse et la discussion des effets observés. La conception de cette formation spécifique s'appuie sur une étude antérieure relative à la résolution de problèmes dans la formation spécifique de traducteurs dont la référence se trouve dans Scott-Tennent et al. (2000) et dans GonzálezDavies et al. (2001).

\section{ABSTRACT}

The aim of this empirical study (carried out as part of a wider research project - see "Credits" below) was to discover the effects of specifically designed pre-service translator training on the trainees' ability to deal with cultural references, a text segment type which is widely considered as potentially problematic for the translator.' Specifically, we set out to discover any significant differences, as a result of said training, in trainees' ability to: (a) detect cultural references within a text, (b) provide multiple feasible options (variants) to translate them, (c) evaluate those potential options, and (d) apply reasoning in making a final choice from the options. The rationale and nature of the specific training involved has already been extensively reported in González Davies and Scott-Tennent (2005). In the present article, we focus our attention on reporting and discussing its observed effects. The design of the specific training drew heavily on a previous study on specific translator training in problem-solving, reported in Scott-Tennent et al. (2000) and González Davies et al. (2001).

\section{MOTS-CLÉS/KEYWORDS}

translation training, cultural references, socio-constructivism, problem-solving, written protocols 


\section{Introduction}

In our previous study $(2000,2001)$, we had found that it was possible to undertake (pre-service) training on solving specific types of translation problem and not only produce a satisfactory learning experience for the participants involved, but also significantly enhance participants' effectiveness in solving the targeted types of problem - in that particular case, (a) lack of lexical (source language-target language) correspondence, (b) lexical phrases, proverbs and idioms, and (c) lack of cohesion and/or coherence. Our initial caution at the time was due to a relatively widespread scepticism we had observed among colleagues towards specific, explicit training in problem-solving (within the context of translator training), which we suspected was most probably due to the teaching methodology which has been traditionally associated with this (all too often drill-like, non-contextualised, non-personalised, nonparticipative, and thus relatively meaningless - and even sometimes tedious - for trainees). In the conclusions of our resulting publications we were able to confidently advocate the inclusion, within Translation/Interpretation education, of the type of training we had studied, on condition, as has just been mentioned, that a teaching methodology informed by humanistic principles and socio-constructivism is used - where knowledge is shared and acquired in a learning environment that enables positive social interaction and includes real life translation projects whenever possible. (Arnold 1999; Ausubel 1963; González Davies 2004; González Davies and Scott-Tennent 2005; Kiraly 2000). By “inclusion” we mean, of course, that this should be one component (among many others) of pre-service translator training and the same time a significant and clearly desirable one.

Once we were confident about the feasibility and desirability of this specific kind of training within the context of translator education, we naturally became more interested in knowing more about its effects. We had seen that trainees' ability to solve specific types of problem could be enhanced by helping them to apply suitable procedures more frequently, but we now wanted to know how this actually occurs. As part of a wider research project (see "Credits"), we focused this time on cultural references as a potentially problematic type of text segment. A prerequisite for the study was thus an operational definition of the concept "cultural reference," which was established, for our purposes as follows:

Any kind of expression (textual, verbal, non-verbal or audiovisual) denoting any material, ecological, social, religious or linguistic manifestation that can be attributed to a particular community (geographic, socio-economic, professional, linguistic, religious, etc.) and would be admitted as a trait of that community by those who consider themselves to be members of it.

This definition was analysed and discussed by the students after they had worked on different proposals to deal with cultural references published within the field of Translation Studies and had debated on the different approaches to the issue of culture, from Contrastive Linguistics to Cultural Studies, also within Translation Studies (Arrojo 2005; Hervey et al. 1995; Hanvey 1992; González Davies and ScottTennent 2005; Nida 1999; Olk 2001). 


\section{Design of the study}

\section{Context}

The participants in this empirical study were a group of 21 students in their third year of the degree (B.A.) program in Translation and Interpreting at the Facultat de Ciències Humanes, Traducció i Documentació at the Universitat de Vic (Barcelona, Spain), taking the course "Literary Translation" (60 contact hours, language pair English-Spanish), who had not received any previous specific, explicit training in problem-solving aspects. It was a naturally occurring group within its setting, not created or modified in any way for purposes of this study.

\section{Nature of specific training}

As already mentioned, we believe a humanistic and socio-constructivist approach to be highly suitable for specific training in problem-solving in order to create a meaningful and memorable learning experience and to produce significant effects on the trainees' ability to translate problematic text segments (a belief which has been progressively confirmed over time). We therefore propose the published full description and commentary of this training process (González Davies and Scott-Tennent 2005) as essential complementary reading to the present article (whose main aim is to report on the empirical study itself carried out in order to observe - and measure objectively - specific effects of said training). We hasten to add, however evident it may seem to some, that it is certainly not our intention to present this kind of training as the only way, or indeed even necessarily as the best way, to develop problemsolving abilities in translators. The complexity and variety which inherently characterise translator education are much more suggestive of complementation, rather than competition, between training methods.

The design of the training drew heavily on a previous study on specific translator training in problem-solving, reported in Scott-Tennent et al. (2000) and González Davies et al. (2001). Major pedagogical features which have been maintained are:

(a) A continuous encouragement of learner autonomy, with the course instructor acting as a guide or counsellor, not as a transmitter of knowledge or as a problem-solver.

(b) Consciousness-raising was sought whenever possible. We believe this is more effectively induced by (i) ensuring that the trainees not only apply the target principles, but also evaluate this application, and (ii) the trainees themselves discovering as many target principles as possible, rather than having them previously presented or explained to them.

(c) The use of authentic materials, i.e., which have not been manipulated for pedagogical purposes.

(d) As much contextualisation as possible for translation tasks. The function of each text was determined before it was translated and, moreover, a specific audience to whom the translation was addressed was generally agreed upon by the students before carrying out the translation. This became a crucial point when carrying out the authentic translation project that formed part of the course (González Davies 2003; González Davies and Scott-Tennent 2005).

(e) The natural integration of our data-gathering instruments (written protocols - see following section of this article) both as a significant part of the experimental training due to their potential consciousness-raising effect, and also, at the same time, within 
the assessment of trainee performance, i.e., for purposes of grading students' coursework.

(f) The training methodology was always applied within our habitually preferred task and project-based, learner-centred, example-oriented approach, with learning resulting from team work and interaction (student-task, students-students and students-teacher), the interaction being moderated and guided, but not led, by the course instructor.

(g) The creation of a positive student-centred working environment characterised by interaction between the students and the students and the teacher.

The explicit aims of this training were twofold:

1. To increase trainees' ability to detect cultural references within a text Methods used to achieve this specific aim were fundamentally: (a) raising awareness, through analysis and discussion, of the existence and nature of cultural references, and (b) fostering a critical, questioning attitude in the reading and comprehension of Source Texts.

2. To increase trainees' ability to deal with any cultural reference which may create a translation problem for them, either in the comprehension of the Source Text (ST) or in the production of their Target Text (TT).

Procedures used to achieve this specific aim were fundamentally: (a) the discovery, analysis, evaluation and application of problem-solving strategies (such as accessing creativity skills, resourcing, comparing, generating and evaluating multiple potential solutions, ...) (b) fostering the adoption of a more (TT) reader-oriented approach or perspective as translators, and (c) the discovery and analysis of existing conventions about the translation of cultural references (see "Introduction").

\section{Aims of this empirical study}

Our aim was to discover any possible objectively measurable significant differences, as a result of the specific training undertaken, in participants' ability, as a group, to: (a) detect cultural references within a text, (b) provide multiple feasible options to translate them, (c) evaluate those potential options, and (d) apply logical reasoning in making a final choice from among the options.

One main reason for choosing to observe effects on these four particular abilities is that we believe them to reflect the four cognitive stages of solving a translation problem. Following Lörscher's conclusions from his empirical study in 1991, we consider a "translation problem" to be present in any text segment that requires conscious attention from the translator, because he/she is not able to transfer it automatically (i.e., without having to stop and think about it). Although we realize that evidently one same segment will not prove to be equally problematic to all translators, and also that not all cultural references will create a problem for translators, it does nonetheless seem clear that cultural references are potentially problematic by their very nature (as cultural differences can often make the search for Source Language - Target Language correspondences less straightforward - see footnote 1), and at the same time it certainly seems reasonable to expect that abilities (b) - (d) listed above can always contribute to an individual's general/overall translation competence. That is, the ability to propose, evaluate, and select from among multiple solutions seems very likely to contribute to increasing the probability of producing an optimal TT segment at any given moment, and is thus to be considered desirable whether or not the translator perceives that segment as problematic. 
Ability (a) listed above reflects our already previously expressed (2000: 108) belief that "the detection of problems is a pre-requisite to problem-solving." Not all cultural references are problematic to translate, but if a translator can more easily spot cultural referents in a text, it seems quite logical to think that he/she is then more likely to detect potential problems whenever they do actually arise. On the other hand, abilities (c) and (d) reflect what is for us a central and essential outcome of translator education in general: informed decisions. By "informed decision," we mean any decision that has: (1) taken into account as many relevant factors as possible (nature and relative importance of references, denotational and connotational meaning, potential TT readers, text function, initiator's expectations, etc.), (2) considered as many feasible solutions as possible, and (3) also applied reasoning in evaluating potential solutions and logical criteria in selecting a final solution. Whenever translator trainers take decisions for their trainees, they are not helping to prepare them for a professional future (where the trainer will no longer be present to take, or even help to take, decisions). Instead, all our efforts should be directed at ensuring that translators' decisions will be as well informed as possible, so as to increase the students' autonomy and self-confidence as translators, and also, in all probability, the quality of their translations.

\section{Procedures}

\section{Pilot study}

A pilot study was first conducted to check on and/or optimise both the training itself and also the efficiency and reliability of the data-gathering instruments and procedures. This in fact allowed for substantial improvements to be made in the second procedure described below. Data-gathering was then considered satisfactory by us when the study was repeated the following academic year. Another additional benefit from the pilot study was to obtain valid data regarding the first procedure described below, which we were later able to contrast with the corresponding data obtained in the definitive study (see "Data analysis and results" below).

\section{Detection of cultural references}

The following (pre-test/post-test) procedure was used to discover any significant differences, as a group, after this specific training, in the trainees' ability to detect cultural references within a text.

In the first session, i.e., even before course presentation, students were given an excerpt of several pages taken from the novel Angela's Ashes (pp. 48-52), after a brief presentation and discussion on the nature of this literary work in order to provide sufficient context for the task, and asked to identify any cultural references they could observe in it (by drawing a circle around the corresponding text segment). This particular text had been selected due to the abundance of such references, not only quantitatively (total number), but also qualitatively (variety of manifestations: material, ecological, social, religious, linguistic). Two other prerequisites had also been met by this text: (a) it was a literary text (as required by the official nature of the course - see "Context" above), and (b) a Spanish language version had previously been made commercially available to the general public (which guaranteed a realistic potential 
translation task, thus excluding, in keeping with this particular pedagogical approach - see "Nature of specific training" above -, any texts which would/might probably never actually be translated in a "real-world" situation). Its length was such that the students were easily able to complete this task within the class session. The students were told that this material would be used later on in the course for pedagogical purposes. No conceptual definition of the expression "cultural reference" was offered at this moment since establishing such a definition was part of the subsequent training, the effects of which we wished to observe.

In the last class session, the same procedure was repeated exactly as described above (i.e., also using exactly the same text). We assume the potential influence of having done this same task once before to be negligible, (1) because of the intervening four-month time gap, (2) because they did not take away a copy of the text the first time (pre-test), (3) because they received no feedback on the pre-test at any time, and (4) because at the moment of doing the pre-test they had no reason to expect they would later be asked to repeat the same task. Another additional measure taken to prevent extraneous variables (factors) from affecting results was to exclude from course content and activities any notably similar literary works to Angela's Ashes, particularly regarding cultural context of its setting.

\section{Proposal of multiple variants, self-evaluation of variants, and final choice}

As mentioned above, data-gathering on these three aspects was found to be problematic in the pilot study. The procedures and instruments designed initially were not considered satisfactory by us in practice, for two reasons: (a) their administration created significant logistical problems, and clearly seemed to require an unreasonable effort from the students, thus possibly (or even probably) causing de-motivation and almost certainly loss of concentration, and (b) instructions and format were found not to be clear enough to the students. Defect (a) had a negative effect on the quantity of data obtained, and we also considered it highly likely that (a) and/or (b) had brought about a negative qualitative effect. Therefore, we decided to discard these particular data and design new procedures, for a second study, which would have to clearly solve these two shortcomings.

Fortunately, this was in fact achieved, by designing a data-gathering instrument which was also simultaneously a learning procedure and an assessment procedure (i.e., counting towards the students' final course grade), integrated within the training process (and also fulfilling institutional requirements) in a natural, coherent and pedagogically beneficial way: the written protocols. Both above-mentioned shortcomings were thus now solved. On the one hand, the students could provide data at home in their own time, and on the other hand, providing these data now became a normal, natural part of their coursework and course assessment requirements, consequently requiring no specific additional time investment on their part (and also, in addition, ensuring that the task would be carried out with a normal level of motivation corresponding to any learning or assessment task). We also significantly reduced the (previously excessive) total duration of the task involved. Defect (b) was solved by writing clearer instructions and ensuring students would have as much time as they needed to read, understand, and if necessary enquire about, these instructions. We found this ecological and student-friendly approach to data-gathering to be visibly 
more efficient and reliable than the more experiment-like data-gathering set-up we had used in the pilot study, and will now always initially consider this possibility in any future studies of this type.

When these written protocols were used as a data-gathering instrument, as may be seen here in the appendix attached to this article, the students were presented with an excerpt (about 400-500 words in length) from a British literary work with a notable presence of a wide range of cultural references: The Growing Pains of Adrian Mole. The criteria for selecting this text were the same as those for selecting Angela's Ashes (see "Detection of cultural references" above). They were asked to imagine themselves as translators into Spanish of this literary work as part of a publication project, and provided with the type of contextual information and brief which would normally be available to translators in such a case. Five segments of the text had been highlighted by us (in each case, a word, phrase, or at most a clause). We had selected these segments following two criteria: (a) they were clearly cultural references according to our operational definition (see "Aims of this empirical study" above) - this condition was to ensure both pedagogical and scientific homogeneity -, and (b) they could potentially be rendered in more than one way. For each of these segments, students were asked to: (1) propose as many feasible renderings as possible, (2) for each of these proposed renderings or variants, list as many pros and cons (potential advantages and disadvantages) as they could think of, (3) make a final choice of one definitive TT rendering from among those they had proposed, and (4) give a brief justification of this choice. A specially-designed grid or table was used to record these data, in order to be visually helpful for the students and also to simplify subsequent extraction of data. This has been shown and commented, including actual examples, in González Davies and Scott-Tennent (2005: 165).

It must be pointed out that in this case, unlike the data-gathering procedure described above in "Detection of cultural references," we did not use exactly the same text in the pre- and post-test. This is because we felt that, after being asked to reflect so deeply on the translation of the target segments, the students might well remember, and thus be influenced by, at least some of their proposals, even after four months. Also, as has already been mentioned, this second data-gathering instrument was presented to the students as a course assignment. Being asked to repeat exactly the same task would not make any kind of sense pedagogically, whereas being asked to do the same task but with a different text (and consequently also different target segments) does clearly make sense pedagogically. We did, of course, try to ensure maximum homogeneity by choosing both extracts from the same literary work, and as similar as possible in content and length. We realized that data might be distorted due to some particular target segments inherently allowing a greater number of potential renderings (variants) than others, but we believed such differences would be mathematically minimized by considering five target segments in each case. Naturally, from a mathematical point of view, the more target segments we considered, the more such potential differences would be minimized, for much the same reasons that a sample is considered more reliable the larger its size. However, at the same time, as has already been explained above, we wished to avoid making excessive demands on the students regarding data production. Taking both these factors into account, five target segments seemed to be the most suitable number. 


\section{Data analysis and results}

\section{Detection of cultural references}

Here, as explained above in the section "Pilot study," we had two valid sets of data, one from the pilot study and one from the full study. Both in the pre-test and in the post-test, the total number was calculated, for each student, of correctly identified cultural references, according to our operational definition. Whenever one same (identical) cultural reference was repeated within the text, its detection was only counted once. Any incorrect "detections" (i.e., where the student incorrectly identified a segment as a cultural reference) were counted as non-detections (i.e., neither adding to nor subtracting from the total of correct detections), since, from the perspective of the aims of our training, neither possibility can potentially contribute to the chances of the student finding an optimal translation for that particular segment. In any case, very few instances were actually found of this in the protocols.

Group mean totals were then calculated for the pre-and post-test, and a (paired) T-test was used to determine whether the difference between the group mean in the pre-test and in the post-test could be considered significant. The T-test type was twotailed, due to the non-directionality of the hypothesis (i.e., we had no clear a priori expectations about the outcome).

In the case of the pilot study, the group mean (of 9 students) for the pre-test was 17.4 correctly identified cultural references, and for the post-test it was 25.4. The $p$-value obtained from the corresponding (paired, two-tailed) T-test was 0.00101194 , denoting an estimated probability of about 1 in 1000 of this difference being due to chance alone. Therefore, the increase in the group mean is clearly to be considered significant, by a very wide margin even following the strictest among the widely accepted criteria $(p<0.01)$, so there can be very little (if any) doubt that as a group, the students were detecting cultural references significantly more often (and thus more effectively) at the end of the training than before the start.

Exactly the same can be said in the case of the full study, where the group mean (of 17 students) for the pre-test was 16.4 , and 21.5 for the post-test, giving a $p$-value of 0.00196288 (probability of about 2 in 1000 of the difference being due to chance alone). This similarity between both outcomes (pilot study and later, full study) additionally, and strongly, reinforces this conclusion (as indeed does any replication of one same test obtaining very similar results).

\section{General criteria for validity of data in the Written Protocols}

As explained above (in "Proposal of multiple options, self-evaluation of options, and final choice"), data for the 3 aspects listed here below were gathered in one same instrument (protocol) - see "Appendix" for further details. From all the raw data thus obtained, the following were subsequently disregarded: (a) cases where the student had not taken both pre- and post-test (standard procedure in this type of design), and (b) any data resulting from a clear (beyond all shade of doubt) miscomprehension of a target ST segment (as evidenced in the student's proposal of possible renderings, or variants). 


\section{Proposal of multiple variants}

The total number of feasible variants was calculated for each student. "Feasible" in this case means any acceptable, though not necessarily ideal, rendering of the target segment. All variants that were not clearly unacceptable (i.e., beyond any shade of doubt) were considered acceptable. This high degree of flexibility was in order to prevent subjectivity (personal preferences on the part of the marker) from inadvertently influencing the criterion. This number was then divided, in each case, by the total number of valid segments. As has also been mentioned in "Proposal of multiple options, self-evaluation of options, and final choice," we asked the students to work on 5 specific segments, but on some occasions, as explained in (b) of the paragraph above, sometimes it was clear that a student had misinterpreted a segment, and we then disregarded all the data pertaining to that segment. The resulting value was the average number of (feasible) variants per (suitably comprehended) segment. As an example, if a student proposed a total of 10 feasible variants for a total of 4 suitably comprehended segments, then he/she was considered to have proposed an average of 2.5 variants per segment.

Group mean totals were then calculated for the pre-and post-test, and a T-test was once again used to decide whether any differences could be considered significant. The group mean "score" for the pre-test was 1.9 variants per segment, and in the posttest it was 2.7 variants per segment. The $p$-value obtained from the corresponding (paired, two-tailed) T-test was 0.00401818 , denoting an estimated probability of about 4 in 1000 of the difference being due to chance alone. Therefore, the increase in the group mean is clearly to be considered significant, by a very wide margin even following the strictest among the widely accepted criteria $(p<0.01)$, so there can be very little (if any) doubt that as a group, the students were proposing significantly more variants (per segment) at the end of the training than before the start.

\section{Self-evaluation of variants}

The total number of valid arguments (pros and cons, advantages and disadvantages) specified was calculated for each student. "Valid" in this case means any such argument that was not clearly erroneous (i.e., beyond any shade of doubt). "Arguments" which were completely generic or tautological (beyond any shade of doubt) were not counted (some examples: "Perhaps, if a better solution could be found, this might not be an adequate solution after all" - as a disadvantage of the variant-, "It doesn't work too well really" - as a disadvantage -, "I don't really like it all that much" - as a disadvantage -, "It's a good translation" - as an advantage). This number was then divided, in each case, by the total number of feasible variants proposed. The resulting value was the average number of (valid) arguments per (feasible) variant. For example, if a student specified a total of 16 valid arguments for a total of 10 feasible variants, then he/she was considered to have specified an average of 1.6 arguments per variant.

Group mean totals were then calculated for the pre-and post-test, and again a T-test was again used to decide whether any differences could be considered significant. In this case, the group mean "score" for the pre-test was 1.2 arguments per variant, and in the post-test it was 1.3 arguments per variant. The $p$-value obtained 
from the corresponding T-test was 0.52875858 , denoting an estimated probability of about 529 in 1000 of the observed difference being due to chance alone. Therefore, the slight increase observed in the group mean can clearly not be considered significant (as it could well be due to chance alone), by a very wide margin even following the least strict among the widely accepted criteria $(p<0.05)$, so there can be very little (if any) doubt that as a group, the students were not specifying significantly more arguments (per variant) at the end of the training than before the start.

\section{Final choice}

The total number of reasonable final choices was calculated for each student. "Reasonable" in this case means any final choice explicitly based on logical criteria (regardless of whether the actual choice coincided or not with the marker's own personal preference). This number was then divided, in each case, by the total number of suitably comprehended segments (i.e., as specified above, any target segments which had not clearly been misinterpreted). The resulting value was then expressed as a percentage, of (reasonable) choices per (suitably comprehended) segment. In (those very rare) cases where only one variant had been proposed for a given segment, there was then no final choice to be made, so neither the final "choice" nor the segment itself were included in these calculations. As an example, if a student specified a total of 3 reasonable final choices for a total of 4 suitably comprehended segments, then he/she was considered to have made $75 \%$ of reasonable final choices.

Group mean totals were then calculated for the pre-and post-test, and a T-test was again used to decide whether any differences could be considered significant. In this case, the group mean "score" for the pre-test was $95.5 \%$ of reasonable final choices, and in the post-test it was $93.2 \%$. The $p$-value obtained from the corresponding T-test was 0.72435001 , denoting an estimated probability of about 724 in 1000 of the observed difference being due to chance alone. Therefore, the slight decrease in the group mean can clearly not be considered significant, by a very wide margin even following the least strict among the widely accepted criteria $(p<0.05)$, so there can be very little (if any) doubt that as a group, the students were not making reasonable choices significantly less (or more) often at the end of the training than before the start.

\section{Conclusions}

As we have seen, in a nutshell, at the end of this training, participants were undoubtedly (a) detecting a significantly greater amount of cultural references within a text, and also (b) proposing a significantly greater amount of feasible variants for the translation of cultural references. However, they were equally undoubtedly not (c) considering a significantly greater amount of relevant pros and cons for each variant, or (d) making a reasonable final choice significantly more often.

The detection of cultural references within a text is such a specific ability that it seems quite unlikely to have been developed elsewhere (outside the specific training whose effects we are observing), and precisely during the same four-month period. On the other hand, as explained above, statistically there is only 1 probability in 1000 in the pilot study, and 2 in 1000 in the full study, that the increase observed in the group mean was due to chance alone (a strict criterion allows up to 10 in 1000). Thus, 
we can conclude that the training itself almost certainly modified that ability positively overall in the group of students.

Regarding the increased ability to propose feasible variants for the translation of cultural references, the probability is only 4 in 1000 (still much lower than a strict 10 in 1000 limit) that this is due to chance alone. We might contemplate the possibility that these students developed elsewhere (i.e., outside this specific training) a general ability to propose more multiple variants when translating (i.e., not just when translating cultural references), and then applied it to this specific type of text segment. But that would be assuming such a general ability does in fact exist, and also that it were possible to modify it significantly in such a short space of time (logically, general abilities should tend to take longer to develop than specific ones). Furthermore, it seems unlikely that they should undergo such a development precisely during the same period as our study took place, even more so if we consider that the rest of their training during that period was relatively heterogeneous (only few of them would be taking exactly the same courses at exactly the same time). Therefore, we can be fairly confident that the significant increase we observed in this group of students was at least largely as a result of this specific training.

Enhanced detection of cultural references will almost certainly, in future practice, include some which are problematic to translate, since this type of segment is widely considered to be potentially problematic (to comprehend fully and/or to render in the TT); and in those cases, knowledge of the nature of the problem (what the problem consists of, what makes it a problem) must logically increase the probability of finding a good solution for it (see González Davies and Scott-Tennent 2005). Proposing a greater number of possible solutions also increases, at the very least from a purely mathematical perspective, the probability of finding a good one. We therefore conclude that the training clearly contributed, at least potentially, to optimal translation of cultural references in this group of students. In any case, few (if any) translator trainers would, we feel, hesitate to view as desirable the development of these two abilities.

On the other hand, it should prove equally interesting, and perhaps even equally fruitful, to consider why this group of students did not show any significant development in their capacity to assess or evaluate the variants they proposed, or in their capacity to apply logical criteria in selecting one of these variants as a final solution, both of which would probably be considered by most translator trainers no less desirable than the other two capacities mentioned above. Evidently, evaluating the variants depends fundamentally on considering all the relevant factors involved (nature and relative importance of references, denotational and connotational meaning, potential TT readers, text function, initiator's expectations, conventions regarding the translation of cultural references, etc), and thus clearly seems an essential part or component of the "informed decision" which we believe increases the probability of producing optimal solutions for translation problems, and should thus ideally be one of the outcomes of translator education (see "Aims of this empirical study" above).

Regarding selection of the most suitable variant, it must be pointed out that, as mentioned in "Final choice" above, logical criteria were being applied $95.4 \%$ of the time already at the start of the training, so, numerically speaking, there was not really much room for improvement anyway. At the same time, from a qualitative perspective, a good final choice requires not only logic in the application of criteria, but also 
correctly weighting the relative importance of each "pro" and "con" previously expressed in the evaluation of the variants. This type of data was often not present in the protocols, but possibly because it was not required explicitly enough in the task instructions. An interesting possibility would be to focus data-gathering in a future study exclusively on final choice, specifically eliciting this "weighting" process, and perhaps then analysing such data qualitatively rather than quantitatively.

It does undoubtedly appear convenient (for the field of translator training) to discover whether these two capacities (evaluating variants and making a final choice) can actually be modified to a significant extent, and if so, when and how.

By "when" we mean at what stage of the development of trainees' translational competence. The students in this study were still relatively far from completing their pre-service training as translators, and indeed defined themselves as either at the "Advanced beginner" stage or at the "Competence stage" (Honey and Mumford 1995; González and Scott-Tennent 2005: 168). Certainly, both evaluating variants and making a final choice form part of what Bloom et al. (1956), in their still widely accepted taxonomy of educational objectives, refer to as "evaluating or judging": they defined this as the ability to judge the worth of material against stated criteria, and located this ability at the very highest level of learning within the cognitive domain.

Regarding the "how," the following related idea, taken from Pym (2003), provides an interesting initial reflection:

[...] whole translation approaches may be related to translating in two ways: they may help translators produce more alternatives than they would otherwise have thought of, and/or they may help them eliminate possible alternatives. Theories would thus be productive or reductive, and both kinds are obviously necessary. Deconstructive theories, for example, are superbly productive but rarely reductive; Skopostheorie in its purest state is eminently reductive but not highly productive, and so on.

If translator training can in fact be more or less productive or reductive, it will be very useful for trainers to know of this cline and bear it in mind. For example, the training we have studied here would then, in view of the effects we have observed and measured, be classed as eminently and strongly "productive," and therefore to be complemented at some stage with eminently "reductive" training. Following Bloom et al. (1956) as to the maximum difficulty of learning to evaluate and judge, the best sequence would seem to be: first productive, later reductive (i.e., with development of trainees' production abilities preceding development of reduction abilities).

Finally, although the quantitative approach followed in this empirical study has allowed us to discover, objectively and with a very high degree of certainty, that the specific training which is fully described and explained in González and Scott-Tennent (2005) enabled a group of students within a naturally occurring humanistic and socioconstructivistic pre-service training context, to detect a significantly greater amount of cultural references within a text, and also to propose a significantly greater amount of feasible variants for the translation of cultural references, interesting aspects have been raised, which we will now investigate using a more qualitative and interpretative methodology. We are currently investigating the nature of individual differences regarding problematic text segments in translation (to what extent different translators find the same segments problematic, and why/why not). Subsequently, we hope to look more closely at ways to help future translators specifically self-evaluate, and make optimal choices from, multiple feasible variants of a TT segment. 


\section{Credits}

This study was part of the educational research project "Educational innovation through the new technologies: foreign languages and translation," funded by the Generalitat de Catalunya (DURSI, DOGC 3275, 20/11/2000, Exp. 21) and by a grant awarded by the University of Vic: "Pedagogia interactiva de la traducció i les llengües estrangeres" 2001-03. We are also grateful to Ms Montserrat Asensio Guasch for her helpful contributions to study design and data processing.

Cette étude empirique fait partie d'un projet de recherche plus large: "Educational innovation through the new technologies: foreign languages and translation," qui a bénéficié d'une aide de la Generalitat de Catalunya (DURSI), DOGC 3275, 20/11/2000, Exp. 21 ainsi que d'une bourse de l'Université de Vic: "Pedagogia...." 2001-03. Nous tenons à remercier Mme Montserrat Asensio Guasch pour ses importantes contributions à l'élaboration du plan de l'étude et au traitement des données.

\section{NOTES}

* This project was partially financed by a research award at the University Ramon Llull.

1. The same group of students involved in this study completed a questionnaire on different aspects of translation in their first and second years of studies. In their first year, 39\% marked "cultural references" as the most problematic aspect of translation; in their second year, the percentage increased to $67 \%$.

\section{REFERENCES}

Arnold, J. (ed.) (1999): Affect in Language Learning, Cambridge, Cambridge University Press.

Arrojo, R. (2005): "The ethics of translation in contemporary approaches to translator training," in Tennent, M. (ed.), Training for the New Millenium, Amsterdam and Philadelphia, John Benjamins.

Ausubel, D. P. (1963): The Psychology of Meaningful Verbal Learning, New York, Grune and Stratton.

Bloom, J., Engelhart, M., Furst, B., Hill, W. and D. Krathwohl (1956): Taxonomy of Educational Objectives, London, Longman.

DAnks, J. (1991): “The psycholinguistics of reading and translation," Fundamental Questions in Translation Theory, University of Leizpig, unpublished manuscript.

GILE, D. (1995): Basic Concepts and Models for Interpreter and Translator Training, Amsterdam and Philadelphia, John Benjamins.

González Davies, M., Scott-Tennent, C. and F. Rodríguez Torras (2001): "Training in the application of translation strategies for undergraduate scientific translation students," Meta 46-4, pp. 737-744.

González Davies, M. (2003a): “Translating Children’s Literature On The Web: An Authentic Project," in Pascua, I. (coord.), Traducción y Literatura Infantil, Las Palmas, Anaga.

González Davies, M. (2004): Multiple Voices in the Translation Classroom. Activities, Tasks and Projects, Amsterdam and Philadelphia, John Benjamins.

González Davies, M. and C. Scott-Tennent (2005): “A problem-solving and student-centred approach to the translation of cultural references," Meta 50-1, pp. 160-179.

Hanvey, R.G. in SCARCella, R.C. and R.L. Oxford (1992): The Tapestry of Language Learning. The Individual in the Classroom, Boston, Heinle and Heinle.

Hervey, S., Higgins, S. and L. Haywood (1995): Thinking Spanish Translation: A Course in Translation Method, London and New York, Routledge.

Honey, P. and A. Mumford (1995): Using your Learning Styles, Maidenhead, Honey.

KIRALY, D. (2000): A Social Constructivist Approach to Translator Education. Empowerment from Theory to Practice, Manchester, St. Jerome. 
Kussmaul, P. (1995): Training the Translator, Amsterdam and Philadelphia, John Benjamins.

LÖrscher, W. (1991): Translation Performance, Translation Process, and Translation Strategies. A Psycholinguistic Investigation, Tübingen, Gunter Narr.

LÖrscher, W. (1992): "Process-oriented research into translation and its implications for translation teaching," Interface: Journal of Applied Linguistics 6-2, pp. 105-117.

McCourt, F. (1996): Angela's Ashes, New York, Simon and Schuster.

NidA, E. (1999): "Language and Culture," Seminar at the Facultat de Ciències Humanes, Traducció i Documentació, University of Vic (Spain).

Olk, H. (2001): The Translation of Cultural References, unpublished Ph.D. Thesis, University of Kent.

Pyм, A. (2003): “Redefining Translation Competence in an Electronic Age," Meta 48-4, pp. 481497.

SÉGUINOT, C. (1991): “A study of student translation strategies," in TirkKonen-Condit, S. (ed.) Empirical Research in Translation and Intercultural Studies, Tübingen, Gunter Narr, pp. 7988.

Scott-Tennent, C., González Davies, M. and F. Rodríguez Torras (2000): “Translation strategies and translation solutions: design of a teaching prototype and empirical study of its results," in Beeby, A., Esinger, D. and M. Presas (eds.), Investigating Translation, Amsterdam and Philadelphia, John Benjamins.

Tirkkonen-Condit, S. (2000): "Uncertainty in translation processes," in TirkKonen-Condit, S. and R. JäÄsKeläninen (eds.), Tapping and Mapping the Processes of Translation and Interpreting, Tübingen, Gunter Narr, pp. 123-132.

Townsend, S. (1984): The Growing Pains of Adrian Mole, London, Methuen.

\section{APPENDIX}

We reproduce here, as completed by one of the students during the study, a sample of the Written Protocol referred to throughout this article, which was used throughout the course simultaneously as a learning activity, as part of institutionally required assessment of student coursework, and as a data-gathering instrument for our study (Pre- and Post-Test), regarding the capacity to: (a) propose multiple feasible TT variants for one same ST cultural reference, (b) identify positive and negative aspects of those variants, and (c) make a logical final choice from among them.

\begin{tabular}{|l|l|l|l|}
\hline $\begin{array}{l}\text { SOURCE TEXT } \\
\text { SEGMENT }\end{array}$ & $\begin{array}{l}\text { PROPOSED } \\
\text { TRANSLATIONS }\end{array}$ & ADVANTAGES & DISADVANTAGES \\
\hline $\begin{array}{l}\text { English } \\
\text { Somprehensive }\end{array}$ & $\begin{array}{l}\text { Instituto de } \\
\text { Enseñanza } \\
\text { Secundaria inglés }\end{array}$ & $\begin{array}{l}\text { It can be easily } \\
\text { associated with the } \\
\text { Spanish Educational } \\
\text { System }\end{array}$ & $\begin{array}{l}\text { Instituto is used only } \\
\text { for State centres. }\end{array}$ \\
\hline & $\begin{array}{l}\text { Colegio de Enseñanza } \\
\text { Secundaria inglés }\end{array}$ & $\begin{array}{l}\text { Colegio is associated } \\
\text { with Primary Schools } \\
\text { or private centres }\end{array}$ \\
\hline & $\begin{array}{l}\text { Centro de Enseñanza } \\
\text { Secundaria inglés }\end{array}$ & $\begin{array}{l}\text { It can be used for any } \\
\text { centre. }\end{array}$ & \\
\hline $\begin{array}{l}\text { FINAL VERSION } \\
\text { Centro de Enseñanza Secundaria inglés }\end{array}$ \\
\hline $\begin{array}{l}\text { JUSTIFICATION OF FINAL VERSION } \\
\text { It is the most neutral and least confusing version. It can be applied to any educational centre. }\end{array}$
\end{tabular}




\section{Instructions}

THE TRANSLATION PROCESS: WRITTEN PROTOCOLS (WP)

A professional translator should not only translate well, but also be able to justify his or her decisions, if necessary. The following Written Protocol has been designed to help you get used to doing this.

Let us view the example to understand how it works:

- in the first column you should write down the corresponding Source Text segment,

- in the second, write down as many different potential translations of it as you can think of,

- in the third, include as many advantages as you can think of for each of your potential translations,

- in the fourth, include as many disadvantages as you can think of for each of your potential translations,

- in the fifth, write down your final choice from among these potential translations, and

- in the sixth column, briefly explain how/why you made your final choice.

You should hand in a WP with each of your individual and group translations (6 WPs throughout the course). Include between THREE and FIVE translation problems in each WP.

Please put them in your group's folder in the bscw shared workspace. Each WP will count as a $10 \%$ of the global mark for the translation.

\section{Translation brief for Pre- and Post-Test assignments}

After a brief initial presentation and discussion on Susan Townsend's Adrian Mole series, students were asked, for the purposes of this specific task, to imagine the following excerpts from The Growing Pains of Adrian Mole (1984) as part of a Spanish language version: (a) commissioned as a stand-alone publication project (that is, not linked or related in any way (stylistically, methodologically) to existing Spanish language versions of other Adrian Mole novels, (b) directed at young teenagers (12-16 years old) as primary target readership, and (c) without any initial constraints on the part of the publisher regarding style, approach, etc. Although this was a simulated context, it was undoubtedly a fully realistic simulation, since, unknown to the students, exactly such a version had been commercialised just before this empirical study was initiated (2002).

\section{Pre-Test Source Text}

Thursday June 3rd

I took Hamish to see how an English comprehensive school works today. The only previous knowledge he had of English schools was taken from reading Tom Brown's Schooldays, so Hamish was a bit disappointed to find that ritual floggings and roastings had been done away with.

Mr Dock, my English teacher, asked Hamish to give our class a short talk on his 'His impressions of England.' Hamish wasn't a bit shy. He went to the front of the class, spat his chewing gum into Mr Dock's wicker basket and said, 'Well, England's great, cute, real fine. Jee-sus it's green! I mean like real green! And I just love your flues [chimneys, translated by Mr Dock]. In the Apple [New York] we don't have flues [chimneys]. I guess the coolest thing, though, is your girls.

Tuesday June $8^{\text {th }}$

Saw Bert Baxter outside the newsagent's. He was sitting in his wheelchair reading the Morning Star. We had a long talk about working-class culture. Bert said that if he were a younger man he would infiltrate into the Sun newspaper and smash the presses up! He tried to get me to join the Young Communists. I said I would think about it. I thought about it for five minutes then decided not to. The GCE examiners might get to hear about it. 
Wednesday September $1^{\text {st }}$

Got a card from Bert Baxter. It was a picture of Bradford Town Hall. Bert had written, Dear Laddo,

Having a good laugh with the old'uns, we are visiting temples and going to weddings nearly everyday. The grub is good but I've had to knock off the drink on account of the other old 'uns' religion.

Queenie is coming out next week. So be a good lad and nip round and give the bungalow a bit of a tidy up.

Yours affec'ly,

Bert

The five target segments selected are marked in bold type: "comprehensive school," "Tom Brown's Schooldays," "Morning Star ... Sun," "Laddo," and "grub."

\section{Post-Test Source Text}

Friday April $9^{\text {th }}$
GOOD FRIDAY

Barry Kent has been spreading malicious rumours that I am addicted to Bostik. His Auntie is a cleaner in the hopital and heard about the nose-stuck-to-model-aeroplane incident. I think it is disgusting that cleaners are allowed to talk about patients' private medical secrets. They should be made to take the Hippocratic oath, like doctors and nurses.

My mother is fed up. She is just sitting around a house smoking and sighing. There was a programme on BBC2 about French babies being born into swimming pools; it was most interesting (and erotic) but my mother quickly switched over to ITV and watched BERNIE WINTERS!!! When I protested she screamed, 'Why don't you clear off and sulk in your room like other teenagers?' [...]

The Canberra has gone to the Falklands and then taken Barry Kent's older brother, Clive, with it.

Sunday July25th

SEVENTH AFTER TRINITY

Did a bit of 'O'level revising. I've got the lousy stinking mocks to do when I get back to school. I am doing English, Geography and History at 'O'level and Woodwork and Domestic Science and Biology at CSE.

Thursday May $27^{\text {th }}$

Got an airmail letter from Hamish Mancini, the American we met on holiday last year.

889 West $33^{\text {rd }}$ Street,

New York

Hi there Aid!

Fazed huh! Yeah well, thought I'd communicate. Been feelin kinda unzapped lately, guess mom's divorce to number four kinda unhinged me some. But! Hamish Mancini aint gonna stick around and take no more adult crap, no sir Aid. I'm comin over to visit you some. I got finance. I got documentation, I got nothin keepin me here. Tomorrow I get a flight and wowee I get to see your olde British cottage in the ancient Midlands region. [...]

See you Saturday buddy.

Hamish Mancini

The five target segments selected are marked in bold type: "Auntie," "BBC2 ... ITV," "The Canberra," "O' Level," and "kinda unhinged me some." 